\title{
Association between tuberculosis, diabetes and 25 hydroxyvitamin D in Tanzania: a longitudinal case control study
}

\author{
Noémie Boillat-Blanco ${ }^{1,2,3,4^{*}}$, Pascal Bovet ${ }^{5}$, Kaushik L. Ramaiya ${ }^{6}$, Maliwasa Mganga', Lilian T. Minja ${ }^{1}$, Lanja Saleh ${ }^{8}$, \\ Medea Imboden ${ }^{2,3}$, Christian Schindler ${ }^{2,3}$, Sebastien Gagneux ${ }^{2,3}$, Claudia Daubenberger ${ }^{2,3}$, Klaus Reither ${ }^{1,2,3}$ \\ and Nicole Probst-Hensch ${ }^{2,3}$
}

\begin{abstract}
Background: Vitamin D level is inversely associated with tuberculosis (TB) and diabetes (DM). Vitamin D could be a mediator in the association between TB and DM. We examined the associations between vitamin D, TB and DM.

Methods: Consecutive adults with TB and sex- and age-matched volunteers were included in a case-control study in Dar es Salaam, Tanzania. Glycemia and total vitamin D $(25(\mathrm{OH}) \mathrm{D})$ were measured at enrolment and after TB treatment in cases. The association between low $25(\mathrm{OH}) \mathrm{D}(<75 \mathrm{nmol} / \mathrm{l})$ and TB was evaluated by logistic regression adjusted for age, sex, body mass index, socioeconomic status, sunshine hours, HIV and an interaction between low 25(OH)D and hyperglycemia.

Results: The prevalence of low 25(OH)D was similar in TB patients and controls ( $25.8 \%$ versus $31.0 \% ; p=0.22$ ). In the subgroup of patients with persistent hyperglycemia (i.e. likely true diabetic patients), the proportion of patients with low 25(OH)D tended to be greater in TB patients (50 \% versus $29.7 \% ; p=0.20$ ). The effect modification by persistent hyperglycemia persisted in the multivariate analysis ( $p_{\text {interaction }}=0.01$ ).
\end{abstract}

Conclusions: Low 25(OH)D may increase TB risk in patients with underlying DM. Trials should examine if this association is causal and whether adjunct vitamin $D$ therapy is beneficial in this population.

Keywords: Stress-induced hyperglycemia, Transient hyperglycemia, Tuberculosis, Vitamin D, Diabetes

\section{Background}

Diabetes mellitus (DM) triples the risk of tuberculosis (TB) and the global increase of DM in developing countries is expected to have an important impact on TB incidence $[1,2]$. Several studies have shown an association between low blood levels of vitamin D with both TB and DM [3-5]. Vitamin D is mainly generated in the skin exposed to sunlight and, to a lower extent, through dietary intake [6]. Vitamin D is usually measured as total blood level of 25 hydroxyvitamin D (25(OH)D) which represents vitamin $\mathrm{D}$ bound to albumin and vitamin $\mathrm{D}$ binding proteins (VDBP) as well as free vitamin $\mathrm{D}$ and does not represent only the levels of the free, active metabolite $\left(1,25(\mathrm{OH})_{2} \mathrm{D}\right)$ which requires

\footnotetext{
*Correspondence: noemie.boillat@chuv.ch

'Ifakara Health Institute, Dar es Salaam, United Republic of Tanzania

${ }^{2}$ Swiss Tropical and Public Health Institute, Basel, Switzerland

Full list of author information is available at the end of the article
}

conversion from $25(\mathrm{OH}) \mathrm{D}$. The free biological active vitamin $\mathrm{D}, 1,25(\mathrm{OH})_{2} \mathrm{D}$, has a short half-life and, therefore, $25(\mathrm{OH}) \mathrm{D}$ measurement is more representative of the vitamin $\mathrm{D}$ status of an individual. However, the level of the free active vitamin $\mathrm{D}$ can be modifiedby the level of binding proteins as well as by the binding affinity of VDBP which is affected by genotype [7].

Vitamin D deficiency was first described as the cause of rickets and osteomalacia. However, the vitamin D receptor is expressed in most cells in the body and vitamin D seems to have an effect on a number of other health outcomes [6]. The association between type $2 \mathrm{DM}$ and low vitamin $\mathrm{D}$ has been described in several crosssectional and prospective studies and a meta-analysis of 21 prospective studies showed an inverse association between blood levels of $25(\mathrm{OH}) \mathrm{D}$ and risk of type $2 \mathrm{DM}$, 
particularly when $25(\mathrm{OH}) \mathrm{D}$ was $<50 \mathrm{nmol} / \mathrm{l}[8]$. Vitamin $\mathrm{D}$ affects pancreatic $\beta$-cell function, boosts the antimicrobial activity of human macrophages against Mycobacterium tuberculosis, and modulates adaptive response [9]. Building on these findings, it was suggested that a low blood level of vitamin D could mediate some of the association between DM and TB [10]. A cross-sectional Indian study confirmed the association between severe vitamin $\mathrm{D}$ deficiency $(<25 \mathrm{nmol} / \mathrm{l}), \mathrm{TB}$ and DM while another study conducted in China did not $[11,12]$.

A trial showed that vitamin D supplementation accelerates the resolution of inflammatory responses during TB treatment and may be used as a host-directed therapy [13]. However, the role of adjunctive vitamin D on TB outcome remains uncertain as several randomized clinical trials of vitamin $\mathrm{D}$ supplementation did not show a beneficial effect on TB outcome or mortality [14-18]. Vitamin D supplementation might have a role in the prevention and treatment of $\mathrm{TB}$ in targeted subgroups of patients with low vitamin D levels, such as diabetic patients.

In this study, we aimed to describe first, the determinants of low vitamin $D$ level among healthy controls and TB patients and, second, the association between TB, vitamin $\mathrm{D}$, and the presence and persistence of hyperglycemia in an African equatorial population.

\section{Methods}

\section{Study design and setting}

This case-control study with longitudinal follow-up of cases was part of a study on the association between TB and DM [19]. In this sub-study, TB patients were recruited between February and December 2013 and followed up for a median time of 5.8 months (IQR 4.7-9.9) after the start of anti-TB treatment. Controls were recruited between March and September 2013 and did not have follow-up visits. Glucose and $25(\mathrm{OH}) \mathrm{D}$ were measured in blood collected at baseline from cases (88 \% before onset of TB treatment) and controls, and in blood collected at follow-up from cases (54\% still under TB treatment). The study was carried out in Kinondoni, the most populated District of Dar es Salaam. Patients were recruited in Mwananyamala Regional Hospital and connected health facilities (Sinza Hospital, Magomeni Health Centre, Tandale Dispensary). Dar es Salaam is located at a latitude of $-6.81^{\circ}$ and longitude of $39.28^{\circ}$ which ensures a good ability of sunlight to synthesize vitamin D [6].

\section{Study participants \\ Cases}

Consecutive adult patients (age $\geq 18$ years; living in Kinondoni District) presenting in the participating hospitals with new active TB diagnosed by the National TB and
Leprosy Control Programme (NTLP) were screened for study inclusion. TB diagnosis was based on sputum smear microscopy, chest X-ray (read by an experienced radiologist), clinical evidence of TB and decision by the clinician to treat with a full-course of anti-TB therapy [20]. TB patients were classified as pulmonary smear-positive, smear-negative or extrapulmonary according to NTLP guidelines [21]. TB patients were treated for 6 months with a standard regimen or longer if necessary $[20,22]$.

\section{Controls}

We used frequency matching on sex and age (10-year age groups) to select controls among adults accompanying patients (other than the one included in the study) to the outpatient departments and living in Kinondoni District. Exclusion criteria were a biological relationship to case, TB history, symptoms or signs of TB, other acute infection or major trauma within the last 3 months.

\section{Study procedures}

Demographic characteristics, DM history and symptoms, socioeconomic status (SES; indicators of education, occupation, wealth using factor analysis), smoking (ever daily smoking), and alcohol misuse ( $\geq$ three drinks per day or $\geq$ six drinks per occasion) were obtained. Daily sunshine hours' data were provided by the Tanzanian meteorological agency. Data were entered directly into an open data kit in a personal digital assistant with real-time error, range and consistency checks [23]. Participants were screened for HIV infection according to the national algorithm (rapid immune-chromatographic test (Alere Determine ${ }^{\text {Tx }}$ HIV-1/2) confirmed by a second rapid test (Trinity Biotech Uni-gold ${ }^{\mathrm{Tm}}$ Recombigen $\left.{ }^{\bullet} \mathrm{HIV}-1 / 2\right)$ ).

\section{Total 25 hydroxyvitamin $D$ measurement}

Serum was kept at $-80{ }^{\circ} \mathrm{C}$ within $6 \mathrm{~h}$ of blood draw and blood 25(OH)D level was assessed by electrochemoluminescence immunoassay (Cobas ${ }^{\circ} 8000$, Roche Diagnostics) in the Institute of Clinical Chemistry at the University Hospital of Zurich in Switzerland. Low blood vitamin $\mathrm{D}$ status was defined as a $25(\mathrm{OH}) \mathrm{D}<75 \mathrm{nmol} / \mathrm{l}$ and vitamin D deficiency as a $25(\mathrm{OH}) \mathrm{D}<50 \mathrm{nmol} / \mathrm{l}[6,24]$. Of note, no patient received vitamin $\mathrm{D}$ replacement therapy.

\section{Hyperglycemia screening}

Blood glucose testing was conducted after an overnight fast of $\geq 8 \mathrm{~h}$ (fasting capillary glucose, FCG) and 2-h glucose in an oral glucose tolerance test (2-hCG; standard 75-g OGTT; GlucoPlus ${ }^{\mathrm{Tm}}$, Diabcare, plasma-calibrated glucometer which accuracy conformed to the International Standardization Organization guidelines) [25]. Abnormal glycemic results (FCG $\geq 5.6 \mathrm{mmol} / \mathrm{l}$ or 2 -hCG $\geq 7.8 \mathrm{mmol} / \mathrm{l}$ ) were confirmed by repeat testing 2 to 
5 days later. For safety reasons, 2-hCG testing was omitted if FCG was $\geq 11.1 \mathrm{mmol} / \mathrm{l}$ and DM was diagnosed. Hyperglycemia refers to patients with repeated FCG $\geq 6.1 \mathrm{mmol} / \mathrm{l}$ and/or 2 -hCG $\geq 7.8 \mathrm{mmol} / \mathrm{l}$ according to WHO [26]. Persistent hyperglycemia was defined based on hyperglycemia measured at enrolment and confirmed at follow-up and is considered a proxy for pre-existing DM. Hyperglycemia detected at enrolment only is more likely to reflect stress hyperglycemia as a result of TB [19]. Participants diagnosed with DM (FCG $>7 \mathrm{mmol} / \mathrm{l}$ or 2-hCG $>11 \mathrm{mmol} / \mathrm{l}$ ) were referred to the local DM clinic, but none was started on DM treatment. Indeed, they all had a fasting glycemia below $10 \mathrm{mmol} / \mathrm{l}$ and it is the usual practice in Tanzania not to treat these patients.

\section{Data analysis}

Characteristics of TB patients were compared to controls. Factors associated with low $25(\mathrm{OH}) \mathrm{D}$ were identified by comparison with participants with a normal level. Differences were tested with Wilcoxon-Mann-Whitney and chi-square tests. The independent association between low 25(OH)D and $\mathrm{TB}$, as well as between persistent hyperglycemia (suggestive of underlying DM) and TB, was evaluated by multivariate logistic regression. We also assessed the interaction between low 25(OH)D and persistent hyperglycemia (suggestive of underlying DM) to examine if the association between $\mathrm{TB}$ and vitamin $\mathrm{D}$ might differ according to underlying DM status.

To assess the combined effect of low 25(OH)D and hyperglycemia, a 4-level categorical variable reflecting the combination of underlying DM and vitamin D status was used as predictor variable in the logistic regression models. Covariates included age, sex, body mass index
(BMI), SES, mean daily sunshine hours during the month of enrolment, HIV status.

Statistical analyses were performed using Stata software (StataCorp, College Station, TX, USA, version 12) and GraphPad Prism 6. $P$ values $<0.05$ were considered as significant.

\section{Results \\ Study sample}

At enrolment, $280 \mathrm{~TB}$ patients and 358 controls had blood sampled for $25(\mathrm{OH}) \mathrm{D}$ and glucose measurement. The final study sample consisted of 167 TB cases with follow-up information and 358 controls, all of whom had complete information on glycemic status, $25(\mathrm{OH}) \mathrm{D}$ and relevant covariates (Fig. 1). Characteristics of the study sample are described in Table 1. Compared to controls, TB patients were more often HIV-infected, previously known for DM and had a lower BMI. At enrolment, hyperglycemia was more common in TB patients than in controls. There was no longer a difference when looking at persistent hyperglycemia, i.e. excluding patients with stress hyperglycemia secondary to TB infection [19]. Among TB patients with hyperglycemia at enrolment, $34 \%(N=13)$ had a FCG and/or 2-hCG in the DM range and $68 \%$ had a normal glycemia after TB treatment although none of them received treatment for DM and only three had lifestyle counselling (Additional file 1: Figure S1). Blood 25(OH)D increased during TB treatment (mean \pm SD increase $6.5 \pm 21 \mathrm{nmol} /, p=0.03$ ) independently of ongoing $\mathrm{TB}$ treatment at the time of measurement (Fig. 2). Correspondingly, the prevalence of low $25(\mathrm{OH}) \mathrm{D}$ decreased $(25.8 \%$ versus $20.4 \%, p<0.001)$.

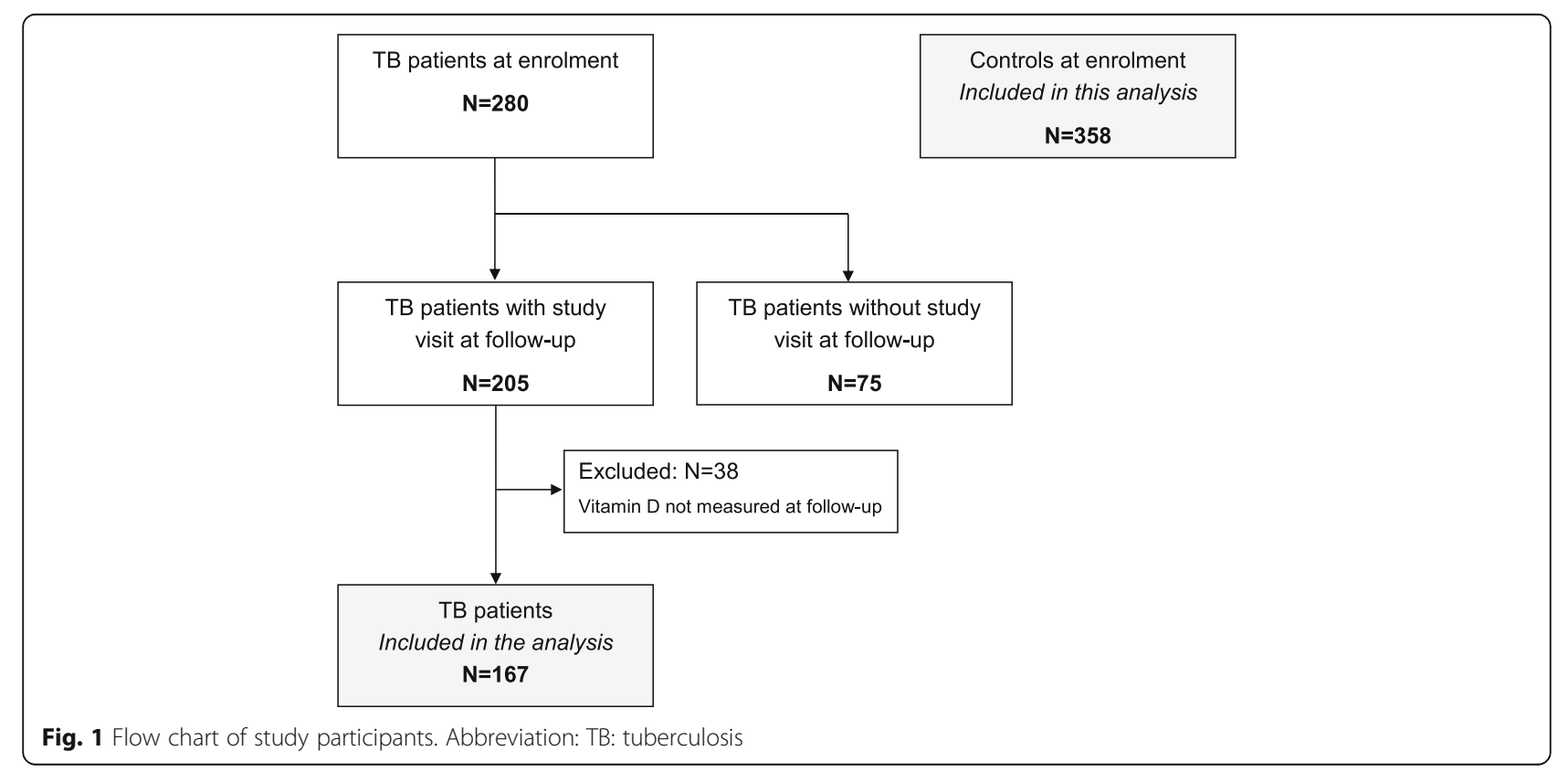


Table 1 Characteristics at baseline of the case-control sample

\begin{tabular}{|c|c|c|c|}
\hline & $\begin{array}{l}\text { TB patients } \\
N=167\end{array}$ & $\begin{array}{l}\text { Healthy controls } \\
N=358\end{array}$ & \multirow[b]{2}{*}{$p$} \\
\hline & \multicolumn{2}{|c|}{ N (\%) or Mean (sd) } & \\
\hline Age & $33.7(10.7)$ & $36.1(13.0)$ & 0.05 \\
\hline Male sex & $95(56.9)$ & $191(53.4)$ & 0.45 \\
\hline History of smoking & $25(15.0)$ & $90(25.3)$ & 0.008 \\
\hline Alcohol misuse & $16(9.6)$ & $22(6.2)$ & 0.16 \\
\hline \multicolumn{4}{|l|}{ Socioeconomic status } \\
\hline Low & $41(24.6)$ & $71(19.9)$ & 0.25 \\
\hline Medium & $82(49.1)$ & $185(52.0)$ & 0.64 \\
\hline High & $44(26.4)$ & $100(28.1)$ & 0.75 \\
\hline $\begin{array}{l}\text { Mean daily sunshine hours } \\
\text { during the month of enrolment }\end{array}$ & $7.9(1.4)$ & $7.9(1.1)$ & 0.08 \\
\hline Body Mass Index (kg/m²) & $22.5(4.2)$ & $25.1(5.1)$ & $<0.001$ \\
\hline HIV infection & $51(30.7)$ & $51(14.3)$ & $<0.001$ \\
\hline Previously known DM & $5(3.0)$ & $2(0.6)$ & 0.02 \\
\hline Hyperglycemia at enrolment & $38(22.8)$ & $37(10.3)$ & $<0.001$ \\
\hline Persistent hyperglycemia & $12(7.2)$ & $37(10.3)$ & 0.33 \\
\hline 25 hydroxyvitamin D deficiency & $3(1.8)$ & $21(5.9)$ & 0.04 \\
\hline Low 25 hydroxyvitamin D & $43(25.8)$ & $111(31.0)$ & 0.22 \\
\hline $\begin{array}{l}25 \text { hydroxyvitamin D level } \\
(\mathrm{nmol} / \mathrm{l})\end{array}$ & $94.0(26.9)$ & $89.6(26.9)$ & 0.08 \\
\hline \multicolumn{4}{|l|}{ TB characteristics } \\
\hline TB symptoms $>3$ months & $21(12.6)$ & & \\
\hline \multicolumn{4}{|l|}{ TB } \\
\hline Smear positive & $136(81.4)$ & & \\
\hline Smear negative & $27(16.2)$ & & \\
\hline Extrapulmonary & $4(2.4)$ & & \\
\hline Cavity on X-ray & 86 (52.8) & & \\
\hline
\end{tabular}

Abbreviations and definitions: TB tuberculosis, Alcohol misuse $\geq 3$ drinks per day or $\geq 6$ drinks per occasion, Socioeconomic status assessed with indicators of scholar education, occupation and wealth ownership using factor analysis, Persistent hyperglycemia presence of hyperglycemia at enrolment confirmed at follow up (measure of glycemia repeated among patients with tuberculosis only), Low vitamin $D<75 \mathrm{nmol} / \mathrm{l}$, Vitamin $D$ deficiency $<50 \mathrm{nmol} / \mathrm{l}$. Hyperglycemia fasting capillary glucose $>6 \mathrm{mmol} / \mathrm{l}$ and/or 2-hCG $>7.7 \mathrm{mmol} / \mathrm{l}$, TB symptoms $>3$ months $>3$ months duration of tuberculosis symptoms. $P$ values were calculated using the Wilcoxon-Mann-Whitney test for continuous variables and chi-square tests for categorical variables

Characteristics and glycemic and vitamin D status of TB patients with and without follow-up were comparable, except for underweight and male sex being more common among subjects without follow-up (Additional file 2: Table S1).

\section{Correlates of low 25(OH)D level}

In the control group, low 25(OH)D was more common in women than in men, but less common in HIV infected persons. In TB patients, low $25(\mathrm{OH}) \mathrm{D}$ was associated with underlying DM (assessed as either a previous

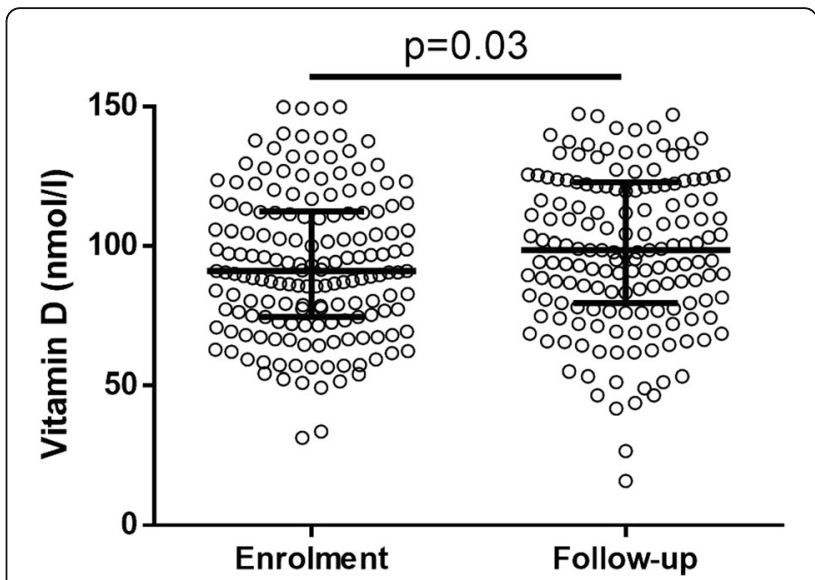

Fig. 2 Categorical scatter plot representing the longitudinal evolution of vitamin D level between baseline and follow-up. Bars represent the $25^{\text {th }}$ percentiles, the median and the $75^{\text {th }}$ percentiles. The difference between enrolment and follow-up was tested with Wilcoxon-Mann-Whitney test. Abbreviation: TB: tuberculosis

DM diagnosis or as persistent hyperglycemia at enrolment and at follow up; Table 2). Level of 25(OH)D was not associated with TB phenotype, but the analysis was limited by a low number of TB patients with extrapulmonary disease.

\section{Association between TB and low 25(OH)D in all subjects and according to persistent hyperglycemia}

Overall, the proportion of patients with a low $25(\mathrm{OH}) \mathrm{D}$ was not statistically different in TB patients compared to controls (25.8\% versus $31.0 \% ; p=0.22)$. In the subgroup of participants with persistent hyperglycemia (i.e. likely true diabetic patients), baseline $25(\mathrm{OH}) \mathrm{D}$ tended to be lower in TB patients than in controls (mean $( \pm \mathrm{SE}$ ) $80.9 \mathrm{nmol} / \mathrm{l} \pm 6.4$ versus $88.8 \mathrm{nmol} / \mathrm{l} \pm 4.8 ; p=0.33$ ) and the proportion of patients with low baseline $25(\mathrm{OH}) \mathrm{D}$ tended to be greater (50\% versus $29.7 \%$; $p=0.20$; Fig. 3). In other words, unadjusted analysis suggests an association of low 25(OH)D with TB status among participants with persistent hyperglycemia.

In contrast, in patients without persistent hyperglycemia, 25(OH)D was higher in TB patients than in controls, irrespective of the time point of vitamin D measurement (mean $( \pm \mathrm{SE}) 95.0( \pm 2.2)$ versus $89.7( \pm 1.5) ; p=$ $0.05)$ and the proportion of patients with low 25(OH)D tended to be lower $(23.9 \%$ versus $31.2 \%$; $p=0.10)$.

Neither low 25(OH)D nor persistent hyperglycemia were associated with an increased risk of TB when occurring in isolation. However, the combination of the two factors was associated with a fourfold increase in the odds of TB compared to patients without the two risk factors. While this difference was not quite statistically significant $(p=0.08)$, the interaction of the two factors was (adjusted OR (95 \% CI): 12.42 (1.78-86.60); 
Table 2 Factors associated with low 25 hydroxyvitamin D level among healthy controls and tuberculosis patients at enrolment

\begin{tabular}{|c|c|c|c|c|c|c|}
\hline & \multicolumn{3}{|l|}{ TB patients $(N=167)$} & \multicolumn{3}{|c|}{ Healthy controls $(N=358)$} \\
\hline & Low 25(OH)D level & Normal 25(OH)D level & & Low 25(OH)D level & Normal 25(OH)D level & \\
\hline & $N=43(25.7 \%)$ & $N=124(74.3 \%)$ & & $N=111(31.0 \%)$ & $N=247(69.0 \%)$ & \\
\hline & N (\%) or Mean (sd) & N (\%) or Mean (sd) & $p$ & $\mathrm{~N}(\%)$ or Mean (sd) & N (\%) or Mean (sd) & $p$ \\
\hline Age & $35.1(12.0)$ & $33.3(10.2)$ & 0.53 & $35.5(12.4)$ & $36.4(13.3)$ & 0.79 \\
\hline Male sex & $20(46.5)$ & $75(60.5)$ & 0.11 & $46(41.4)$ & $144(58.8)$ & 0.002 \\
\hline History of smoking & $4(9.3)$ & $21(16.9)$ & 0.23 & $25(22.5)$ & $65(26.8)$ & 0.40 \\
\hline Alcohol misuse & $0(0)$ & $7(5.7)$ & 0.11 & $3(2.7)$ & $19(7.7)$ & 0.07 \\
\hline \multicolumn{7}{|l|}{ Socioeconomic status } \\
\hline Low & $11(25.6)$ & $30(24.2)$ & 0.84 & $17(15.3)$ & $54(22.2)$ & 0.2 \\
\hline Medium & $22(51.2)$ & $60(48.4)$ & 0.86 & $57(51.4)$ & $127(52.3)$ & 1 \\
\hline High & $10(23.3)$ & $34(27.4)$ & 0.84 & $37(33.3)$ & $62(25.5)$ & 0.13 \\
\hline $\begin{array}{l}\text { Mean daily sunshine hours during the } \\
\text { month of enrolment }\end{array}$ & $8.2(1.2)$ & $7.9(1.4)$ & 0.26 & $7.9(1.0)$ & $7.9(1.1)$ & 0.22 \\
\hline Body mass index $\left(\mathrm{kg} / \mathrm{m}^{2}\right)$ & $19.8(3.1)$ & $20.4(3.9)$ & 0.54 & $25.8(5.5)$ & $24.9(4.8)$ & 0.11 \\
\hline HIV infection & $12(27.9)$ & $39(31.7)$ & 0.64 & $6(5.4)$ & $45(18.4)$ & 0.001 \\
\hline Previously known for DM & $4(9.3)$ & $1(0.8)$ & 0.005 & $0(0)$ & $2(0.8)$ & 0.34 \\
\hline Hyperglycemia at enrolment & $9(20.9)$ & $29(23.4)$ & 0.74 & $11(9.9)$ & $26(10.5)$ & 0.86 \\
\hline Persistent hyperglycemia & $6(14.0)$ & $6(4.8)$ & 0.05 & & & \\
\hline \multicolumn{7}{|l|}{ TB characteristics } \\
\hline TB symptoms $>3$ months & $8(18.6)$ & $13(10.5)$ & 0.17 & & & \\
\hline \multicolumn{7}{|l|}{ TB } \\
\hline Smear positive & $36(83.7)$ & $100(80.7)$ & 0.82 & & & \\
\hline Smear negative & $6(14.0)$ & $21(16.9)$ & 1 & & & \\
\hline Extrapulmonary & $1(2.3)$ & $3(2.4)$ & 1 & & & \\
\hline Cavity on X-ray & $20(48.8)$ & $66(54.1)$ & 0.56 & & & \\
\hline
\end{tabular}

Abbreviations and definitions: $25(\mathrm{OH}) \mathrm{D} 25$ hydroxyvitamin $\mathrm{D}$, Low vitamin D level $<75 \mathrm{nmol} / \mathrm{l}$, Alcohol misuse $\geq 3$ drinks per day or $\geq 6$ drinks per occasion Socioeconomic status assessed with indicators of scholar education, occupation and wealth ownership using factor analysis, DM diabetes, Persistent hyperglycemia presence of hyperglycemia at enrolment and at follow up (measure of glycemia repeated among patients with tuberculosis only). Hyperglycemia fasting capillary glucose $>6 \mathrm{mmol} / \mathrm{l}$ and/or 2-hCG $>7.7 \mathrm{mmol} / \mathrm{l}$, TB symptoms $>3$ months $>3$ months duration of tuberculosis symptoms before diagnosis.

$P$ values were calculated using the Wilcoxon-Mann-Whitney test for continuous variables and chi-square tests for categorical variables

$\mathrm{p}_{\text {interaction }}=0.01$; Table 3). Additional adjustment for the month of recruitment had no effect on the results presented in Table 3 .

The interaction was not significant when using the continuous value of 25(OH)D (adjusted OR (95\% CI): $0.97(0.93-1.01)$; $\left.p_{\text {interaction }}=0.09\right)$.

\section{Discussion}

In this black sub-Saharan equatorial population, we provide novel evidence for the association between low 25(OH)D and TB among persons with persistent hyperglycemia, irrespective of HIV status. In contrast, 25(OH)D levels were higher in TB cases compared to controls in normoglycemic participants. The longitudinal design of this study reinforces the validity of our findings as it makes possible to differentiate between persons with only transient hyperglycemia possibly related to the acute phase of inflammation versus participants with persistent hyperglycemia who are likely truly diabetic patients. ().

The associations between low vitamin $\mathrm{D}$ status and DM, low vitamin D status and TB as well as TB and DM have been demonstrated in many studies. These data point to vitamin $\mathrm{D}$ as a potential mediator in the link between DM and TB which is consistent with our results [10]. Our data are also concordant with an Indian study showing that the prevalence of severe vitamin $D$ insufficiency $(<25 \mathrm{nmol} / \mathrm{L})$ was higher among TB patients with DM compared to those without DM [11]. However, in our study, the definition of low vitamin $\mathrm{D}$ was different $(<75 \mathrm{nmol} / \mathrm{L})$ as most participants had a high $25(\mathrm{OH}) \mathrm{D}$ concentration. The absence of an association between $\mathrm{DM}$ and $25(\mathrm{OH}) \mathrm{D}$ among healthy controls may be explained by the low statistical power related to the low numbers of diabetic patients. Our longitudinal study underlines the limitations of studying the combined 


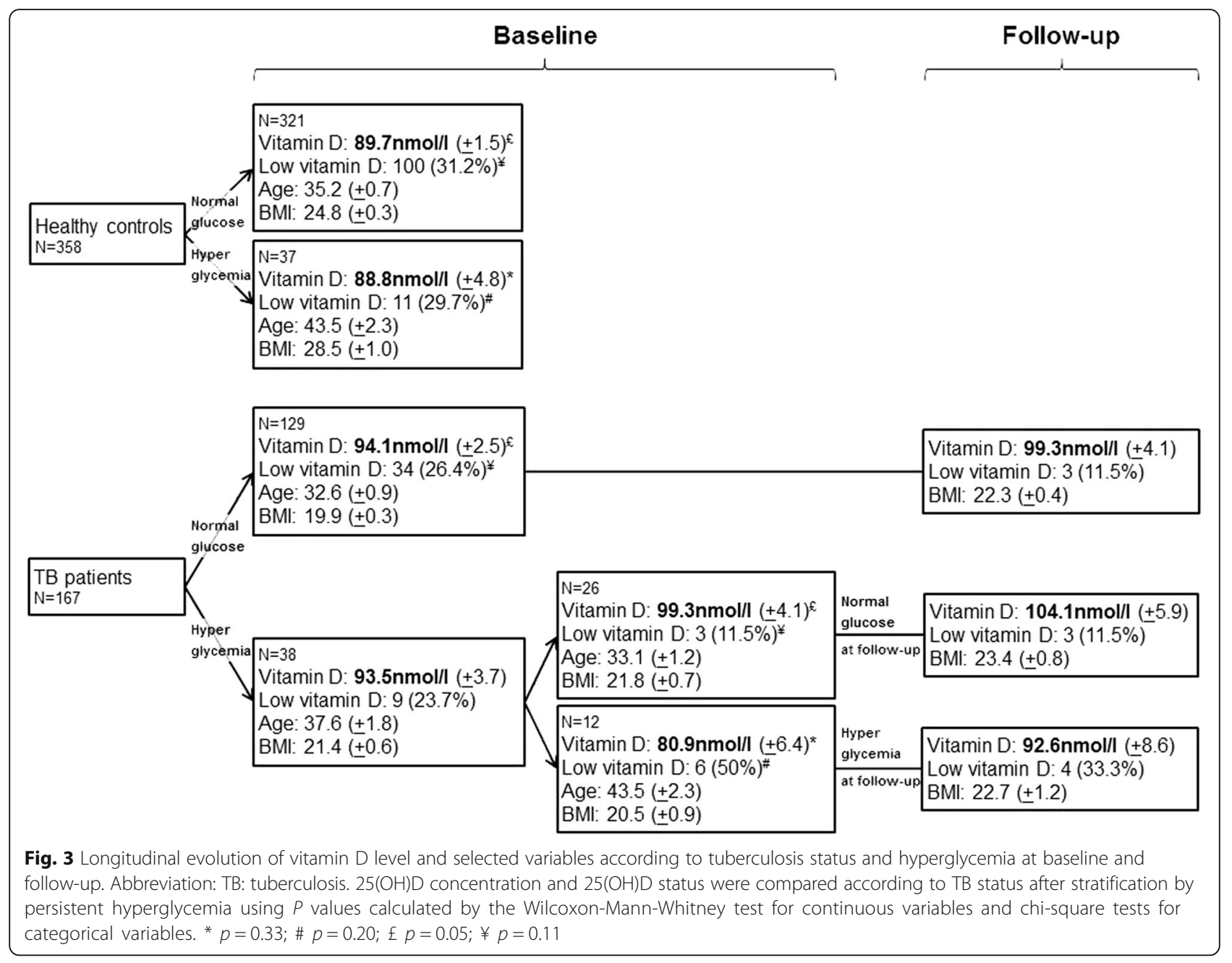

impact of circulating glucose and $25(\mathrm{OH}) \mathrm{D}$ on $\mathrm{TB}$ in a cross-sectional manner only (i.e. based on data at baseline only). At the time of diagnosis of active TB, the inflammation status can influence hyperglycemia (stress-induced hyperglycemia) and likely also 25(OH)D levels (e.g. through induction of $25(\mathrm{OH}) \mathrm{D}$ metabolism or transient changes in the blood levels of proteins bound to $25(\mathrm{OH}) \mathrm{D}$ ) $[19,27,28]$. Hence, cross-sectional studies may miss the importance of DM (persistent hyperglycemia) in the association between TB and vitamin D status [19]. Consistent with two other studies, 25(OH)D level increased during TB treatment in our study, despite the described lowering effect of isoniazid and rifampicin on blood vitamin $\mathrm{D}$ [29-31]. The improved vitamin D status during TB treatment may be related to greater sun exposure and dietary intake of vitamin D during recovery. However,

Table 3 Association with tuberculosis in different patients' categories according to vitamin D and glycemic status

\begin{tabular}{lll}
\hline & Association with tuberculosis \\
\cline { 2 - 3 } Normal 25 hydroxyvitamin D level and absence of persistent hyperglycemia & Adjusted OR (95\% Cl) & $P$ value \\
Low 25 hydroxyvitamin D level and absence of persistent hyperglycemia & Ref. & $0.70(0.41-1.20)$ \\
Normal 25 hydroxyvitamin D level and persistent hyperglycemia & $0.46(0.15-1.44)$ & 0.20 \\
Low 25 hydroxyvitamin D level and persistent hyperglycemia & $4.0(0.86-18.54)$ & 0.18 \\
\hline
\end{tabular}

Interaction factor between low 25 hydroxyvitamin D and persistent hyperglycemia: adjusted OR $(95 \% \mathrm{Cl}) 12.42(1.78-86.60) ; \mathrm{p}_{\text {interaction }}=0.01$

${ }^{a}$ Adjusted for age, sex, body mass index, socioeconomic status, mean daily sunshine hours during the month of enrolment and HIV status.

Low vitamin D level $<75 \mathrm{nmol} / \mathrm{l}$, Persistent hyperglycemia presence of hyperglycemia at enrolment confirmed at follow up (measure of glycemia repeated among patients with tuberculosis only).

Adjusted odds ratios and $p$ values were calculated using multivariate logistic regression 
results related to $25(\mathrm{OH}) \mathrm{D}$ have to be interpreted carefully, as $25(\mathrm{OH}) \mathrm{D}$ mainly reflects protein-bound vitamin $\mathrm{D}$ and may not represent the level of free active form of vitamin D. During inflammation, similarly to levels of several other blood acute-phase proteins, the concentration of albumin decreases and might modify $25(\mathrm{OH}) \mathrm{D}$ result [27], while one study showed no change in blood VDBP during the first 8 weeks of TB treatment [28]. Further studies should examine the relation between TB, diabetes and vitamin $\mathrm{D}$ based on levels of free vitamin $\mathrm{D}$.

The importance of low blood levels of vitamin D as a risk factor for the development of TB was suggested in a prospective cohort study conducted among HIVinfected adults in Tanzania [32]. Several case control studies also reported a lower blood $25(\mathrm{OH}) \mathrm{D}$ in TB patients compared to control groups [33, 34]. However, consistent with a large study conducted in Mwanza, Tanzania, we observed an increased 25(OH)D among TB patients compared to healthy controls, particularly after treatment of TB [29]. Also, contrary to many studies elsewhere, mean $25(\mathrm{OH}) \mathrm{D}$ was in the normal range in the Tanzanian studies, possibly because of higher vitamin $\mathrm{D}$ levels in a tropical country with high exposure to UVB compared to countries remote of the Equator, which may have limited the potential impact of low $25(\mathrm{OH}) \mathrm{D}$ on TB to only the group of diabetic patients who had lower 25(OH)D levels [35]. Indeed, vitamin D deficiency varies between studies conducted in Africa, ranging from $4.3 \%$ in Tanzania to $62.7 \%$ in South Africa [33].

Our study has several strengths. First, the longitudinal design allowed assessing the association between TB, $\mathrm{DM}$ and vitamin $\mathrm{D}$ after resolution of inflammation, which influences glycemic status. Indeed, many TB patients with hyperglycemia at baseline have a normal glycemia after TB treatment which suggests that many cross-sectional studies on the association between TB and DM probably overestimate the increased TB risk associated with DM. The study population was well defined and the patients categorized according to WHO recommendations. Our study also has limitations. First, we performed the measurement of total $25(\mathrm{OH}) \mathrm{D}$ and not its active form $\left(1,25(\mathrm{OH})_{2} \mathrm{D}\right)$ [7]. TB diagnosis was based on NTLP guidelines and smear results rather than culture or GenXpert. However, the study was conducted under the real case scenario of TB treatment in this population. Fasting and 2-h glucose were assessed on capillary whole blood using a point-of-care test and not in venous blood. However, we used a plasma-calibrated glucometer the accuracy of which conformed to the International Standardization Organization guidelines [25]. Another limitation of our study is that healthy controls did not have a follow-up assessment of their glycemic status. However, we did not expect a temporal modification of DM status over 5 months' follow-up in the general population as we included only participants who did not present any acute infection or major trauma within the last 3 months. We used persistent hyperglycemia as a proxy of $\mathrm{DM}$ in $\mathrm{TB}$ patients to exclude patients with stress hyperglycemia secondary to TB infection. This definition may have missed some DM patients who had improvement of their glycemic status by changing their lifestyle during the follow-up period. However, very few patients $(N=3)$ went to the DM clinic and had lifestyle counselling and it is unlikely that it significantly contributed to our results. Vitamin D deficiency was recently identified as a probable risk factor for extrapulmonary TB [36]. However, the number of TB patients with this phenotype was very low in our study and did not allow any subgroup analysis. The impact of 25(OH)D level on TB outcome is controversial and adjunctive vitamin $\mathrm{D}$ may improve $\mathrm{TB}$ outcome in subgroups of patients only [15, 18, 31, 37]. Unfortunately, we did not have the power to look at the effect of the interaction between low $25(\mathrm{OH}) \mathrm{D}$ and persistent hyperglycemia on TB outcome.

\section{Conclusions}

In this equatorial population with a high mean $25(\mathrm{OH}) \mathrm{D}$ concentration $(91 \mathrm{nmol} / \mathrm{L})$, a low blood level of $25(\mathrm{OH}) \mathrm{D}(<75 \mathrm{nmol} / \mathrm{L})$ seems to increase the risk of TB only in the context of persistent hyperglycemia. Diabetic patients might be an appropriate target for vitamin $\mathrm{D}$ supplementation to improve TB outcome or prevent active $\mathrm{TB}$, but the benefit of such interventions requires confirmation through randomized controlled trials.

\section{Additional files}

Additional file 1: Figure S1. Longitudinal evolution of glycemic status among tuberculosis patients between enrolment (left bar) and follow up (right bar). Abbreviation: pre-DM: pre-diabetes, defined as fasting capillary glucose between 6.1 and $7 \mathrm{mmol} / \mathrm{l}$ and/or 2-h capillary glucose between 7.8 and $11.0 \mathrm{mmol} / \mathrm{l}$; DM: diabetes, defined as fasting capillary glucose $>7 \mathrm{mmol} / \mathrm{l}$ and/or 2 -h capillary glucose $>11.0 \mathrm{mmol} / \mathrm{l}$, according to $\mathrm{WHO}$ recommendation. (JPG $46 \mathrm{~kb}$ )

Additional file 2: Table S1. Characteristics of the TB patients with and without follow-up. (DOCX $15 \mathrm{~kb}$ )

\section{Abbreviations \\ 1,25(OH) 2 D: 1,25-Dihydroxyvitamin D; 2h-CG: 2-h capillary glucose after standard oral glucose tolerance test; 25(OH)D: 25-hydroxyvitamin D; $95 \%$ Cl: 95 \% Confidence interval; aOR: Adjusted odds ratio; BMl: Body mass index; DM: Diabetes mellitus; FCG: Fasting capillary glucose; NTLP: National tuberculosis and leprosy control programme; OGT: Oral glucose tolerance testing; pre-DM: Pre-diabetes; SD: Standard deviation; SES: Socio-economic status; TB: Tuberculosis; WHO: World Health Organization}

\section{Acknowledgments}

We thank all the patients who accepted to participate and make this study possible. We thank all the clinical officers, nurses and recruiters of Ifakara Health Institute and Mwananyamala Hospital who worked hard for this study. We also thank the NTLP team of Mwananyamala Hospital, Sinza Hospital, Magomeni Health Care Center and Tandale Dispensary for 
their active participation in the study. We thank the Medical Officers in charge of Mwananyamala Hospital, Sinza Hospital, Magomeni Health Care Center and Tandale Dispensary for their support throughout the study. We thank Dr Izhak Kimaro for reading the X-rays of all TB patients. We thank Evelyn Fischer for her support in samples handling. We thank Prof T. Calandra, head of Infectious Diseases Service at Lausanne University Hospital, and Prof. M. Tanner, head of the SwissTPH, for their support and positive input on this research.

\section{Funding}

Swiss National Science Foundation (grants \# PBLAP3-139981 and PBLAP3-145866), MSD Merck Sharp \& Dohme AG, SICPA Foundation, Academic Society of Lausanne.

No role of funding bodies in the study.

\section{Availability of data and materials}

Participants did not approve to public availability of data, but data are available upon individual requests to the author.

\section{Authors' contributions}

NBB, NPH: contributed to study conception, study design, study performance, study management, data analysis, data interpretation and manuscript writing. KR: contributed to study conception, study design, study performance, study management, data interpretation and critical review of the manuscript. CD, SG: contributed to study conception, study design, study performance, data interpretation and critical review of the manuscript. CS, PB: contributed to data analysis, data interpretation and critical review of the manuscript. MM, LTM, KLR, LS: contributed to interpretation of the data and critical review of the manuscript. All authors read and approved the final manuscript.

\section{Competing interests}

The authors declare that they have no competing interests.

\section{Consent for publication}

\section{Not applicable.}

\section{Ethics approval and consent to participate}

All participants gave written informed consent prior to the interview and health examination. The Ifakara Health Institute Institutional Review Board (IHI/IRB/N: 10-2012) and the Medical Research Coordinating Committee of the National Institute for Medical Research, Tanzania (NIMR/HQ/R.8a/Nol. IX/ 1340), gave ethical clearance.

\section{Author details}

${ }^{1}$ Ifakara Health Institute, Dar es Salaam, United Republic of Tanzania. ${ }^{2}$ Swiss Tropical and Public Health Institute, Basel, Switzerland. ${ }^{3}$ Department of Sciences, University of Basel, Basel, Switzerland. ${ }^{4}$ Infectious Diseases Service, Lausanne University Hospital, Lausanne, Switzerland. ${ }^{5}$ Institute of Social and Preventive Medicine, Lausanne University Hospital, Lausanne, Switzerland. ${ }^{6}$ Shree Hindu Mandal Hospital and Muhimbili University of Health Sciences, Dar es Salaam, United Republic of Tanzania. ${ }^{7}$ Kinondoni Municipal Council, National Tuberculosis Program, Dar es Salaam, United Republic of Tanzania. ${ }^{8}$ Institute of Clinical Chemistry, University of Zurich, University Hospital of Zurich, Zurich, Switzerland.

Received: 18 May 2016 Accepted: 25 October 2016 Published online: 03 November 2016

\section{References}

1. Jeon CY, Murray MB. Diabetes mellitus increases the risk of active tuberculosis: a systematic review of 13 observational studies. PLoS Med. 2008;5(7):e152.

2. Wild S, Roglic G, Green A, Sicree R, King H. Global prevalence of diabetes: estimates for the year 2000 and projections for 2030. Diabetes Care. 2004;27(5):1047-53.

3. Martineau AR. Old wine in new bottles: vitamin D in the treatment and prevention of tuberculosis. Proc Nutr Soc. 2012;71(1):84-9.

4. Pilz S, Kienreich K, Rutters F, et al. Role of vitamin D in the development of insulin resistance and type 2 diabetes. Curr Diab Rep. 2013;13(2):261-70.
5. Xuan Y, Zhao HY, Liu JM. Vitamin D and type 2 diabetes mellitus (D2) J Diabetes. 2013;5(3):261-7.

6. Rosen CJ. Clinical practice. Vitamin D insufficiency. N Engl J Med. 2011;364(3):248-54.

7. Powe CE, Evans MK, Wenger J, et al. Vitamin D-binding protein and vitamin D status of black Americans and white Americans. N Engl J Med. 2013;369(21):1991-2000.

8. Song Y, Wang L, Pittas AG, et al. Blood 25-hydroxy vitamin D levels and incident type 2 diabetes: a meta-analysis of prospective studies. Diabetes Care. 2013;36(5):1422-8.

9. Hawn TR, Shah JA, Kalman D. New tricks for old dogs: countering antibiotic resistance in tuberculosis with host-directed therapeutics. Immunol Rev. 2015;264(1):344-62

10. Handel AE, Ramagopalan SV. Tuberculosis and diabetes mellitus: is vitamin D the missing link? Lancet Infect Dis. 2010;10(9):596.

11. Chaudhary S, Thukral A, Tiwari S, Pratyush DD, Singh SK. Vitamin D status of patients with type 2 diabetes and sputum positive pulmonary tuberculosis. Indian J Endocrinol Metab. 2013;17 Suppl 3:S670-3.

12. Zhan Y, Jiang L. Status of vitamin D, antimicrobial peptide cathelicidin and $T$ helper-associated cytokines in patients with diabetes mellitus and pulmonary tuberculosis. Exp Ther Med. 2015;9(1):11-6.

13. Coussens AK, Wilkinson RJ, Hanifa Y, et al. Vitamin D accelerates resolution of inflammatory responses during tuberculosis treatment. Proc Natl Acad Sci U S A. 2012;109(38):15449-54.

14. Kota SK, Jammula S, Tripathy PR, Panda S, Modi KD. Effect of vitamin D supplementation in type 2 diabetes patients with pulmonary tuberculosis. Diabetes Metab Syndr. 2011;5(2):85-9.

15. Martineau AR, Timms PM, Bothamley GH, et al. High-dose vitamin D(3) during intensive-phase antimicrobial treatment of pulmonary tuberculosis: a double-blind randomised controlled trial. Lancet. 2011;377(9761):242-50.

16. Nursyam EW, Amin Z, Rumende CM. The effect of vitamin D as supplementary treatment in patients with moderately advanced pulmonary tuberculous lesion. Acta Med Indones. 2006;38(1):3-5.

17. Wejse C, Gomes VF, Rabna P, et al. Vitamin D as supplementary treatment for tuberculosis: a double-blind, randomized, placebo-controlled trial. Am J Respir Crit Care Med. 2009;179(9):843-50.

18. Daley $\mathrm{P}$, Jagannathan $\mathrm{V}$, John $\mathrm{KR}$, et al. Adjunctive vitamin $\mathrm{D}$ for treatment of active tuberculosis in India: a randomised, double-blind, placebocontrolled trial. Lancet Infect Dis. 2015;15(5):528-34.

19. Boillat-Blanco N, Ramaiya KL, Mganga M, et al. Transient hyperglycemia in patients with tuberculosis in Tanzania: implications for diabetes screening algorithms. J Infect Dis. 2016;213(7):1163-72.

20. URTanzania. United Republic of Tanzania. National Tuberculosis and Leprosy Programme and Ministry of Health and Social Welfare. Manual for the Management of Tuberculosis and Leprosy. 2013; 6th Ed.

21. NTLP. National Tuberculosis and Leprosy Programme and Ministry of Health and Social Welfare. The United Republic of Tanzania Ministry of Health and Social Welfare National Tuberculosis and Leprosy Programme annual report. http://ntlpgotz/indexphp?option=com_phocadownload\&view= category\&id=10:annualreports\&ltemid=139. 2013. Accessed 25 Oct 2016.

22. WHO. Treatment of tuberculosis guidelines. 4th ed. Geneva: World Health Organization; 2010.

23. Hartung CA, Brunette W, Lerer A, Tseng C, Borriello G. Open Data Kit: building information services for developing regions. London: International Conference on Information and Communication Technologies for Development (ICTD); 2010.

24. Holick MF, Binkley NC, Bischoff-Ferrari HA, et al. Evaluation, treatment, and prevention of vitamin D deficiency: an Endocrine Society clinical practice guideline. J Clin Endocrinol Metab. 2011;96(7):1911-30.

25. Essack Y, Hoffman M, Rensburg M, Van Wyk J, Meyer CS, Erasmus R. A comparison of five glucometers in South Africa. JEMDSA. 2009;14(2):102-5.

26. WHO. Definition and diagnosis of diabetes mellitus and intermediate hyperglycaemia. 2006.

27. Ceciliani F, Giordano A, Spagnolo V. The systemic reaction during inflammation: the acute-phase proteins. Protein Pept Lett. 2002;9(3):211-23.

28. Coussens AK, Wilkinson RJ, Nikolayevskyy V, et al. Ethnic variation in inflammatory profile in tuberculosis. PLoS Pathog. 2013;9(7):e1003468.

29. Friis H, Range N, Changalucha J, et al. Vitamin D status among pulmonary TB patients and non-TB controls: a cross-sectional study from Mwanza, Tanzania. PLoS One. 2013;8(12):e81142. 
30. Koo HK, Lee JS, Jeong YJ, et al. Vitamin D deficiency and changes in serum vitamin D levels with treatment among tuberculosis patients in South Korea. Respirology. 2012;17(5):808-13.

31. Sloan DJ, Mwandumba HC, Kamdolozi M, et al. Vitamin D deficiency in Malawian adults with pulmonary tuberculosis: risk factors and treatment outcomes. Int J Tuberc Lung Dis. 2015;19(8):904-11.

32. Sudfeld CR, Giovannucci EL, Isanaka S, et al. Vitamin D status and incidence of pulmonary tuberculosis, opportunistic infections, and wasting among HIV-infected Tanzanian adults initiating antiretroviral therapy. J Infect Dis. 2013;207(3):378-85.

33. Martineau AR, Nhamoyebonde $S$, Oni T, et al. Reciprocal seasonal variation in vitamin D status and tuberculosis notifications in Cape Town, South Africa. Proc Natl Acad Sci U S A. 2011;108(47):19013-7.

34. Nnoaham KE, Clarke A. Low serum vitamin D levels and tuberculosis: a systematic review and meta-analysis. Int J Epidemiol. 2008:37(1):113-9.

35. Durazo-Arvizu RA, Camacho P, Bovet $P$, et al. 25-Hydroxyvitamin D in African-origin populations at varying latitudes challenges the construct of a physiologic norm. Am J Clin Nutr. 2014;100(3):908-14.

36. Pareek M, Innes J, Sridhar S, et al. Vitamin D deficiency and TB disease phenotype. Thorax. 2015;70(12):1171-80.

37. Davies PD, Martineau AR. Vitamin D and tuberculosis: more effective in prevention than treatment? Int J Tuberc Lung Dis. 2015;19(8):876-7.

\section{Submit your next manuscript to BioMed Central} and we will help you at every step:

- We accept pre-submission inquiries

- Our selector tool helps you to find the most relevant journal

- We provide round the clock customer support

- Convenient online submission

- Thorough peer review

- Inclusion in PubMed and all major indexing services

- Maximum visibility for your research

Submit your manuscript at www.biomedcentral.com/submit 